OPEN ACCESS

Edited by:

Christen Kerry Mirth,

Monash University, Australia

Reviewed by:

Abid Ali,

University of Agriculture, Pakistan

Anna-Maria Botha-Oberholster,

Stellenbosch University, South Africa

Kwang Pum Lee,

Seoul National University,

South Korea

*Correspondence:

Frédéric Francis

frederic.francis@uliege.be

Julian Chen

chenjulian@caas.cn

tThese authors have contributed equally to this work and share first authorship

Specialty section:

This article was submitted to Evolutionary Developmental Biology,

a section of the journal

Frontiers in Ecology and Evolution

Received: 13 October 2021

Accepted: 27 January 2022

Published: 18 February 2022

Citation:

Sun J, Tan X, Li Q, Francis F and Chen J (2022) Effects of Different

Temperatures on the Development

and Reproduction of Sitobion miscanthi From Six Different Regions

in China.

Front. Ecol. Evol. 10:794495 doi: 10.3389/fevo.2022.794495

\section{Effects of Different Temperatures on the Development and Reproduction of Sitobion miscanthi From Six Different Regions in China}

\author{
Jingxuan Sun ${ }^{1,2,3 \dagger}$, Xiaoling Tan ${ }^{1 \dagger}$, Qian $\mathrm{Li}^{1}$, Frédéric Francis ${ }^{2 *}$ and Julian Chen ${ }^{1 *}$ \\ 'State Key Laboratory for Biology of Plant Diseases and Insect Pests, Institute of Plant Protection, Chinese Academy \\ of Agricultural Sciences (CAAS), Beijing, China, ${ }^{2}$ Functional and Evolutionary Entomology, Gembloux Agro-Bio Tech, \\ University of Liège, Gembloux, Belgium, ${ }^{3}$ Mudanjiang Branch of Heilongjiang Academy of Agricultural Sciences, Mudanjiang, \\ China
}

The increase in temperature caused by global warming has greatly impacted plant growth and pest population dynamics worldwide, especially for wheat aphids. In this study, Sitobion miscanthi individuals from six geographic populations located in different wheat-producing areas in China were compared with regard to their growth, development, survival, and reproductive under different temperature conditions (17, 22 and $27^{\circ} \mathrm{C}$ ). A population life-table analysis and a correlation analysis between geographic factors and S. miscanthi longevity or fecundity were also performed. Temperature significantly affected the nymphal development duration (NDD), the adult longevity (ALY) and the fecundity (AFY) of the aphids, however, latitude can only affect the NDD and ALY. There is an obvious interaction between temperature and latitude on the NDD, ALY, and AFY. The NDD in the three northern populations was significantly shorter than that in the southern populations. The ALY in northern populations was significantly longer than that in southern populations at different temperatures. Except for Yinchuan population was no significantly different under different degrees, the ALY of other populations was significantly shortened at $27^{\circ} \mathrm{C}$. The AFY of northern populations was significantly lower than that of southern populations at $22^{\circ} \mathrm{C}$, while significantly higher at $27^{\circ} \mathrm{C}$. With the increase of temperature, the fecundity of northern population gradually decreased from 17 to $22^{\circ} \mathrm{C}$, while the southern population suddenly decreased at $27^{\circ} \mathrm{C}$. The curves of survival rate $\left(s_{x j}\right)$ in southern populations were significantly shorter than that of northern population. Especially the populations in Suzhou and Wuhan, in which the survival rate decreased rapidly at $27^{\circ} \mathrm{C}$. Age-specific survival rate $\left(I_{x}\right)$ of southern populations began to decline rapidly on 15 days of age at $27^{\circ} \mathrm{C}$, while those of northern populations were not significantly affected until on 20 days of age. The highest peaks of age-stage fecundity $\left(f_{x j}\right)$, age-specific fecundity $\left(m_{x}\right)$, and age-specific net maternity $\left(I_{x} m_{x}\right)$ were occurred in northern populations. In addition, there was a positive correlation between latitude and longevity under the three degrees, however, only at $27^{\circ} \mathrm{C}$, there was a positive correlation between latitude and fecundity. Our result proved that the 
higher reproductive rate of southern population requires aphids to live at the suitable ambient temperature, and aphid populations in the north have a wider ecological amplitude. The results will be helpful for predicting the potential aphid outbreaks in China's main wheat areas under suitable conditions.

Keywords: Sitobion miscanthi, geographic population, longevity, temperature, development, reproduction

\section{INTRODUCTION}

Wheat is a major crop worldwide in temperate regions (Kirkegaard et al., 2008; Nirmal et al., 2017). The main production bases for high-quality wheat in China are located on the Yellow-Huai-Hai Plain and the North China Plain (Jin et al., 2021). Aphids cause severe crop yield reductions and result in significant economic losses each year (Wang et al., 2014). Sitobion miscanthi (Takahashi) (Hemiptera: Aphididae), a major insect pest in temperate regions, has a short development cycle and a high reproductive rate (Raychaudhuri et al., 1973; Turak et al., 1998; Hawkes and Jones, 2005; Singh et al., 2009; Wang et al., 2009; Hales et al., 2010; Chen et al., 2011). S. miscanthi is anholocyclic in most geographic areas. In rare cases, there are sexual forms: an ovipara (sexual female) collected on Persicaria chinensis in India may be S. miscanthi (David, 1975). In Japan and Korea, Sitobion akebiae may be a synonym, although S. akebiae is holocyclic (lays overwintering eggs). However, the taxonomy of the miscanthi and akebiae groups needs further clarification. The evidence for holocycly requires confirmation (Blackman and Eastop, 1984). Temperature is an important abiotic factor that affects aphid populations and biological parameters, including insect growth and development (Osawa, 1993; Nyaanga et al., 2005; Del and Reisig, 2013; Zhu et al., 2017). The optimal growth rate and development cycle of aphids require an adapted temperature range (Bernard et al., 2018; Wang et al., 2021). For example, for codling moths, the optimal range is between 10 and $30^{\circ} \mathrm{C}$ (Rock and Shaffer, 1983). The optimal range for egg, larval and egg-to-adult development of Spodoptera frugiperda recorded is between 26 and $32^{\circ} \mathrm{C}$ (Plessis et al., 2020). Under extremely harsh natural conditions, aphids initiate diapause adaptation strategies (Denlinger, 2002; Kroschel et al., 2013; Ma and Ma, 2016). In ectotherms, environmental temperatures influence the organism's biochemical reactions, with direct consequences for life history traits (Hochachka and Somero, 2002). Some studies show a correlation between the optimal thermal value and the mean temperature of locations by latitudinal or geographical analysis at intra- and interspecific levels (Angilletta, 2009).

Environmental temperature affects the function and adaptability of ectotherms, revealing that the distribution of organisms is mainly limited by their thermal fitness (Huey and Kingsolver, 1993; Angilletta, 2009). Studying how ectotherms adapt to different thermal environments is particularly important to understand changes in life history (Clarke, 1993). "The hotter the better" hypothesis states that the higher the optimal temperature is, the higher the maximum thermal performance of the organism should be (Huey and Kingsolver, 1989). The hypothesis predicts that optimal thermal performance will lead to maximum performance at the most frequently experienced body temperature. Therefore, the genotype of the hot environment has a higher thermal optimization than that of the cold environment.

The fitness cost investigation included life histories (developmental time, fecundity, fertility, and population growth), metabolism and behavior. Among them, life-table analyses are a means of determining the population characteristics that predict population growth and describing developmental characteristics such as reproductive rates and life expectancies in a pest population (Davison et al., 2010; Hajar et al., 2011; Liao et al., 2017; Han et al., 2019). The effect of temperature on aphids has been reported under laboratory conditions with respect to some host plants. The optimum temperature for the growth and development of grain aphids, Sitobion avenae, is $15-25^{\circ} \mathrm{C}$, at which the highest intrinsic growth rate $\left(r_{m}\right)$ results (Ahn et al., 2020). The highest $r_{m}$ and finite rate of increase in Acyrthosiphon pisum (Harris) (Hemiptera: Aphidoidea) were observed at $25^{\circ} \mathrm{C}$ (Luis and Xavier, 2001). Some studies have reported that temperature affects aphid behavior and biochemical parameters (Ma and Ma, 2012; Chen et al., 2013). However, few studies have involved the effects of multiple factors, such as temperature and latitude, on aphid biology and ecology.

Given that temperature and geographic factors may play important roles in the evolution of insects, measuring the life history traits of different populations under a series of developmental temperatures can reveal the adaptation of traits to general temperature conditions. In an effort to estimate the influence of the net effects of changing climate scenarios, the positive and negative effects of temperature changes on insects need to be considered. Elevated temperature will bring them closer to their physiologically optimal state, and insects at high latitudes may have higher adaptability (Kingsolver, 2009). The impact on populations at low latitudes is little known (Deutsch et al., 2008; Stange and Ayres, 2010). Insects at low latitudes may suffer declines in growth, fecundity, and fitness in summer.

The aphids were exposed to three constant temperatures $\left(17,22\right.$, and $\left.27^{\circ} \mathrm{C}\right)$. The optimal temperature of S. miscanthi is approximately $22^{\circ} \mathrm{C}$, while the other two temperatures are increased and decreased by $5^{\circ} \mathrm{C}$ versus this temperature value, making them within the range of the optimum temperature threshold for the aphid. Based on the hypothesis that higher temperature will eventually exceed physiologically optimal states, we predict that the longevity and fecundity of S. miscanthi will decrease with increasing temperature. Therefore, in this study, the effects of three constant temperatures $\left(17,22\right.$, and $27^{\circ} \mathrm{C}$ ) on the development and reproduction of different geographic 
populations of S. miscanthi were evaluated. This is expected to help predict area-wide aphid outbreaks.

\section{MATERIALS AND METHODS}

\section{Aphid Colonies}

Aphid populations were collected from wheat plants in six major wheat-producing areas in China, namely, Suzhou (SZ), Wuhan (WH), Kunming (KM), Tai'an (TA), Langfang (LF), and Yinchuan (YC), by a five-point sampling method from February to April 2018. The aphids were brought back to the laboratory and transferred to wheat seedlings (aphid-susceptible cultivar). Newborn nymphal aphids from adults were transferred to new aphid-free wheat (cutivar, Hengguan 35) seedlings to continue feeding. The aphids produced 3-5 generations under lab conditions before the experiments and were stably reproduced to achieve clonal homogeneity. Plants were grown in controlled environmental chambers at $22 \pm 1^{\circ} \mathrm{C}$, with $75 \pm 5 \%$ relative humidity $(\mathrm{RH})$ and a $16 \mathrm{~h}$ photoperiod under a light intensity of $9000 l_{x}$.

\section{Wheat Plants}

The wheat cultivar Hengguan 35 was used as the host plant for aphid rearing. Wheat seedlings were updated every 2 weeks to maintain aphid reproduction. Nutrient soil and loess were sterilized, mixed with vermiculite at a ratio of 2:1:1 and placed in pots. Ten full-grain wheat seeds were then sown in each pot $(20 \mathrm{~cm}$ in diameter). When the wheat plants had grown to $5 \mathrm{~cm}$, aphids were inoculated into five vigorous seedlings. Temperature and humidity conditions were similar to those related to aphid rearing.

\section{Experimental Conditions}

Aphids were reared on wheat leaves in three artificial climate rooms at 17,22 , and $27^{\circ} \mathrm{C}$, and previous relative humidity and photoperiod conditions were maintained. One adult aphid was individually placed onto a wheat leaf at the two-leaf stage and covered with a microcage. Each treatment included five pots, and four adult aphids were inoculated into each pot. Each treatment was repeated three times. After the nymphs were born, the adults were removed, and all nymphs in each pot were at the same developmental stage.

The aphids were observed twice at 8:00 and 20:00 every day. The number and instars of nymphs as well as the developmental duration of each instar were recorded. The number of aphids produced was recorded until all the adults had died.

\section{Data Analysis}

Nymphal development duration, adult longevity, aphid longevity, and fecundity were analyzed using ANOVA. Linear correlation analysis was used between the latitudes of six places and the fecundity of $S$. miscanthi. ANCOVA with temperature as the main factor and latitude as the covariate was used to analyze the effects of temperature and latitude on the nymphal development duration, adult longevity, aphid longevity, and fecundity of $S$. miscanthi. The experimental data are expressed as the mean \pm standard error (SE). Duncan's new multiple range test at $P<0.05$ was used to compare the means and to determine the significance of differences between variables. Life history data on the development, surviva and fecundity of $S$. miscanthi were analyzed according to the age-stage, two-sex life table theory (Huang and Chi, 2012). The computer program TWOSEX-MSChart (Chi and Su, 2006) was used to obtain the age-stage-specific survival rate $\left(s_{x j}\right)\left(s_{x j}\right.$ is the probability that a newly laid egg can survive to age $x$ and develop to stage $j$ where $x$ is the age and $j$ is the stage), which was calculated as:

$$
s_{x j}=\frac{n_{x j}}{n_{01}}
$$

The age-specific survival rate $l_{x}$ represents survivorship of the original cohort over the age interval from day $x-1$ to day $x$. $m_{x}$ denotes the mean number of female offspring produced per surviving female during the age interval $x$.

$$
l_{x}=\sum_{j=1}^{k} s_{x j}
$$

The fecundity $\left(f_{x j}\right)$ (the number of eggs laid by female adult at age $x$ ),

$$
f_{x j}=\frac{E_{x j}}{n_{x j}}
$$

The age-specifc fecundity $\left(m_{x}\right)$ is calculated as:

$$
m_{x}=\frac{\sum_{j=1}^{m} s_{x j} f_{x j}}{\sum_{j=1}^{m} s_{x j}}
$$

The reproductive rate $\left(R_{0}\right)$ and the intrinsic rate of population increase $\left(r_{m}\right)$ were calculated by using the Euler-Lotka equation (Maia Ade et al., 2000). $R_{0}, r_{m}$, the generation average period $(T)$, the weekly growth rate $(\lambda)$ were calculated (Suleman and Reisen, 1979; Wei et al., 2018). To obtain stable and precise estimates, we used 1,00,000 bootstraps. The data were analyzed using SPSS statistical software, version 26.0 (SPSS, Inc., Chicago, IL, United States). Graphs were produced using GraphPad Prism 8 biostatistics software (GraphPad Software Inc., San Diego, CA, United States).

\section{RESULTS}

\section{Distribution of Sampling Locations and Their Basic Information}

In the geographical division of China, the northern and southern regions of China are divided by the Qinling Mountains and the Huaihe River. Insect samples were obtained from six populations located in the main wheat-producing areas of China, among which three (SZ, WH, and $\mathrm{KM}$ ) belong to southern populations and the other three (TA, LF, and YC) to northern populations. The sample information, including the names of the collection places, latitudes and mean annual temperature, is shown (Figure 1). 


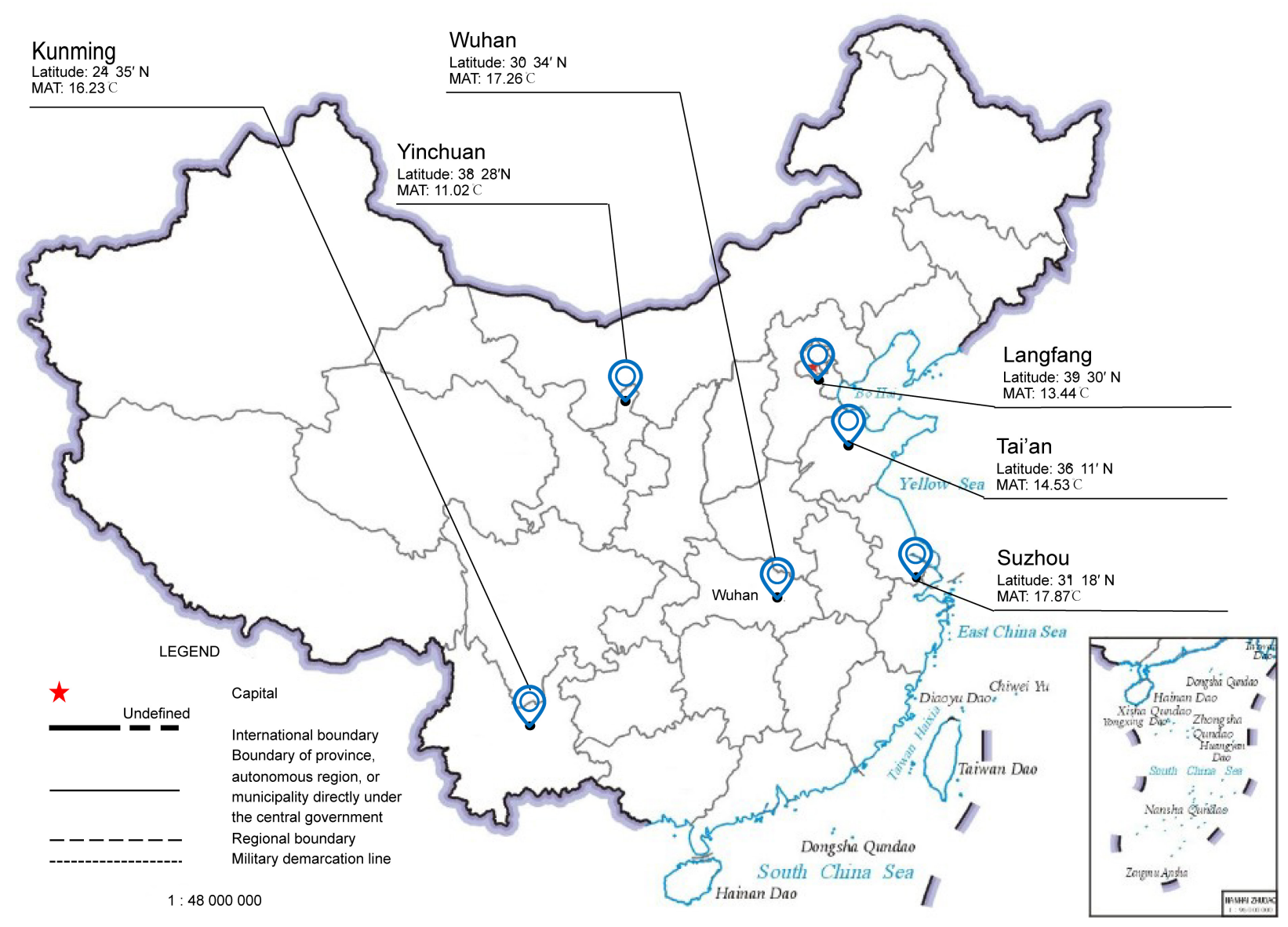

FIGURE 1 | Map of China showing the locations of the sampling sites and the mean annual temperature (MAT) were calculated on 2015 and 2018 period.

\section{Effect of Temperatures and Latitude on Nymphal Development Duration of Sitobion miscanthi}

Temperature and latitude significantly affected the nymphal development duration (NDD) of the aphids, there is an obvious interaction between temperature and latitude (Table 1). The populations of Suzhou and Wuhan had the longest NDD among the six populations at the three temperatures (Figure 2). At each temperature, the NDD in the three northern populations was significantly shorter than that in the southern populations. Among the southern population, The NDD of Kunming population was significantly shorter than that of the other two. In northern populations, the NDD was not significantly different $\left(17^{\circ} \mathrm{C}: F=18.729, d f=5,354, P<0.001 ; 22^{\circ} \mathrm{C}\right.$ : $F=2.405, d f=5,354, P=0.042 ; 27^{\circ} \mathrm{C}: F=37.434, d f=5,354$, $P<0.001)$ (Figure 2).

Different temperatures have different effects on NDD in different regions. the NDD of southern population was significantly shortened both at 22 and $27^{\circ} \mathrm{C}$, while the northern population was shortened only at the highest $27^{\circ} \mathrm{C}$ (SZ: $F=11.770, d f=2,357, P<0.001 ; \mathrm{WH}: F=4.512, d f=2,357$, $P<0.05 ; \mathrm{KM}: F=11.795, d f=2,357, P<0.001 ; \mathrm{TA}: F=9.732$, $d f=2,357, P<0.001 ;$ LF: $F=17.125, d f=2,357, P<0.001 ;$ YC: $F=15.683, d f=2,357, P<0.001)$.

\section{Effect of Temperatures and Latitude on Adult Longevity of Sitobion miscanthi}

Temperature and latitude significantly affected the adult longevity (ALY) of aphids. There is an obvious interaction between temperature and latitude (Table 1). The ALY in northern populations was significantly longer than that in southern populations at different temperatures, except for the population of Kunming is no significant difference with the population in Langfang $\left(17^{\circ} \mathrm{C}: F=15.827, d f=5,354, P<0.001 ; 22^{\circ} \mathrm{C}\right.$ : $F=8.552, d f=5,354, P=0.042 ; 27^{\circ} \mathrm{C}: F=48.380, d f=5,354$, $P<0.001$ ) (Figure 3).

Except for the ALY of Yinchuan population was no significantly different under different degrees, the ALY of other populations was significantly shortened at the highest $27^{\circ} \mathrm{C}$, The ALY of population in Suzhou, Wuhan and Tai'an was longest at 17 and $22^{\circ} \mathrm{C}$, and Kunming and Langfang are 22 and $17^{\circ} \mathrm{C}$, respectively. While the southern population suddenly decreased at $27^{\circ} \mathrm{C}$, which decreased greatly more than northern population. (SZ: $F=33.591, d f=2,357, P<0.001 ; \mathrm{WH}: F=77.747, d f=2,357$, 
TABLE 1 | The effects of temperature and latitude on the nymphal development duration, adult longevity, longevity and fecundity of S. miscanthi (ANCOVA analysis with temperature as the main factor and latitude as the covariate).

\begin{tabular}{llccc}
\hline Variable & Source & df & $\boldsymbol{F}$ & $\boldsymbol{P}$ \\
\hline $\begin{array}{l}\text { Nymphal development } \\
\text { duration (D) }\end{array}$ & Temperature & 2 & 18.735 & $<0.001$ \\
& & & & \\
& Latitude & 1 & 156.368 & $<0.001$ \\
& Temperature*Latitude & 2 & 15.055 & $<0.001$ \\
& Temperature & 2 & 66.558 & $<0.001$ \\
Adult longevity (D) & Latitude & 1 & 170.332 & $<0.001$ \\
& Temperature*Latitude & 2 & 21.135 & $<0.001$ \\
& Temperature & 2 & 89.397 & $<0.001$ \\
Longevity (D) & Latitude & 1 & 77.591 & $<0.001$ \\
& Temperature*Latitude & 2 & 15.757 & $<0.001$ \\
& Temperature & 2 & 91.293 & $<0.001$ \\
Fecundity & Latitude & 1 & 2.584 & 0.109 \\
& Temperature*Latitude & 2 & 37.344 & $<0.001$ \\
\hline
\end{tabular}

${ }^{1}$ Temperatures: 17,22 and $27^{\circ} \mathrm{C} ;{ }^{2}$ Latitudes: $24.59^{\circ} \mathrm{N}$ (Kunming), $30.58^{\circ} \mathrm{N}$ (Wuhan), $31.3^{\circ} \mathrm{N}$ (Suzhou), $36.19^{\circ} \mathrm{N}$ (Tai'an), $38.47^{\circ} \mathrm{N}$ (Yinchuan), $39.5^{\circ} \mathrm{N}$ (Langfang).

$P<0.001 ; \mathrm{KM}: F=48.834, d f=2,357, P<0.001$ TA: $F=14.369$, $d f=2,357, P<0.001 ; \mathrm{LF}: F=4.977, d f=2,357, P<0.001 ; \mathrm{YC}$ : $F=1.120, d f=2,357, P<0.05)$.

\section{Effects of Temperature and Latitude on the Fecundity of Sitobion miscanthi}

Aphid fecundity (AFY) was significantly affected by temperature. There was no significantly effect of latitude on the AFY. There is an obvious interaction between temperature and latitude (Table 1). There was no significantly effect of latitude on the AFY at $17^{\circ} \mathrm{C}$, however, there are significantly effect of latitude on the AFY at both of the higher temperature. $\left(17^{\circ} \mathrm{C}: F=0.908\right.$, $d f=5,354, P=0.479 ; 22^{\circ} \mathrm{C}: F=5.037, d f=5,354, P<0.001$; $\left.27^{\circ} \mathrm{C}: F=24.083, d f=5,354, P<0.001\right)$. The fecundity of northern populations was significantly higher than that of southern populations at $27^{\circ} \mathrm{C}$ (Figure 4).

The AFY of Kunming and Suzhou in the southern population was significantly higher than that of the northern population at $22^{\circ} \mathrm{C}$. At $27^{\circ} \mathrm{C}$, Yinchuan had the highest fecundity $(33.06 \pm 2.14$ a), and the lowest fecundity was observed from Wuhan $(11.11 \pm 1.43 \mathrm{~d})$. The fecundity of the southern population was significantly lower than that of the northern population (Figure 5A). With the increase of temperature, the fecundity of northern population gradually decreased from 22 to $27^{\circ} \mathrm{C}$, and there's not much difference between 22 and $27^{\circ} \mathrm{C}$. While the southern population suddenly decreased at $27^{\circ} \mathrm{C}$, which decreased greatly. (SZ: $F=27.138, d f=2,357, P<0.001$; WH: $F=75.373, d f=2,357, P<0.001 ; \mathrm{KM}: F=25.129, d f=2,357$, $P<0.001$; TA: $F=18.590, d f=2,357, P<0.001$; LF: $F=10.309$, $d f=2,357, P<0.001$; YC: $F=3.484, d f=2,357, P<0.05)$.

The correlation of aphid fecundity with latitude at different treated temperatures was analyzed and is shown in Figure 5A. Based on the correlation coefficient data, the fecundity of the aphids and latitude were significantly negative at $22^{\circ} \mathrm{C}$ $\left(r^{2}=0.7906, p=0.018<0.05\right)$. However, fecundity and latitude had no statistical significance at $17^{\circ} \mathrm{C}\left(r^{2}=0.4483\right.$, $p=0.146>0.05)$ and $27^{\circ} \mathrm{C}\left(r^{2}=0.6456, p=0.054>0.05\right)$.

The correlation of aphid longevity with latitude at different treated temperatures was analyzed and is shown in Figure 5B. Based on the correlation coefficient data, the longevity and latitude of the aphids were significantly positive at $17^{\circ} \mathrm{C}$ $\left(r^{2}=0.8389, p=0.010<0.05\right)$ and $27^{\circ} \mathrm{C}\left(r^{2}=0.8271\right.$, $p=0.012<0.05)$. However, longevity and latitude had no statistical significance at $22^{\circ} \mathrm{C}\left(r^{2}=0.4545, p=0.142>0.05\right)$.

\section{Effects of Different Temperatures on the Life-Table Parameters of Sitobion miscanthi}

The influence of latitude on the $r_{\mathrm{m}}$ values was complicated at $17^{\circ} \mathrm{C}$, however, at $22^{\circ} \mathrm{C}$, the $r_{\mathrm{m}}$ of the southern population was high (SZ: $0.220 \pm 0.001$; WH: $0.203 \pm 0.001$; KM: $0.223 \pm 0.001$ ). At $27^{\circ} \mathrm{C}$, the $r_{\mathrm{m}}$ of the northern population was high (TA: $0.213 \pm 0.001$; LF: $0.223 \pm 0.001$; YC: $0.227 \pm 0.001)$. The $R_{0}$ value of the southern populations was lower than that of the northern populations at $27^{\circ} \mathrm{C}$ (Table 2). There was no significant difference between the southern and northern populations at $17^{\circ} \mathrm{C}$. The $\lambda$ values of the populations were not significantly different.

The age-stage specific survival rate $\left(s_{x j}\right)$ represents the probability of a newborn individual surviving to age $x$ and stage $j$. The stage overlaps observed in $s_{x j}$ clearly showed the variable developmental rate occurring among individuals (Figure 6). The curves of southern populations for adult duration at $27^{\circ} \mathrm{C}$ were significantly shorter than that of northern population at $27^{\circ} \mathrm{C}$. Especially the populations in Suzhou and Wuhan, the survival rate decreased rapidly at adult stage at $27^{\circ} \mathrm{C}$ (Figure 6A). The survival rates of northern populations were not affected by rising temperatures (Figure 6B).

It is shown that $s_{x j}$ is a detailed survival rate showing the stage differentiation, however, the age-specific survival rate $l_{x}$ curve is the summation of the survival curves at different stages at age $\mathrm{x}$, and it is the simplified version of $s_{x j}$ means all stage structure is ignored and all stages are pooled. The $l_{x}$, age-stage fecundity $\left(f_{x j}\right)$, age-specific fecundity $\left(m_{x}\right)$, and age-specific net maternity $\left(l_{x} m_{x}\right)$ in different populations at different degrees are shown in Figure 7. $l_{x}$ of southern populations began to decline rapidly on 15 days of age at $27^{\circ} \mathrm{C}$, while those of northern populations were not significantly affected until on 20 days of age. The highest peaks of age-stage fecundity $\left(f_{x}=7\right)$ occurred on Day 10 in Tai' an of northern population at $17^{\circ} \mathrm{C}$, the second highest peak $f_{x}$ $\left(f_{x}=5.94\right)$ occurred on Day 10 in Yinchuan at $27^{\circ} \mathrm{C}$ (Figure $7 \mathbf{B}$ ). The highest peaks of $f_{x}$ in Southern population occurred on Day 13 in Wuhan with 5.61 offspring at $22^{\circ} \mathrm{C}$ (Figure 7A). The highest peaks of $m_{x}\left(m_{x}=5.94\right)$ occurred on day 10 in Yinchuan of northern population at $27^{\circ} \mathrm{C}$ (Figure $7 \mathbf{B}$ ). the second peak value was 5.61 on day 13 in Wuhan of southern population at $22^{\circ} \mathrm{C}$. The third was Suzhou with a fertility value of 5.4 on Day 18 at $17^{\circ} \mathrm{C}$ (Figure 7A). By factoring in the survival rate, the highest agespecific maternity values $\left(l_{x} m_{x}\right)$ were 5.94 on Day 10 in Yinchuan of northern population at $27^{\circ} \mathrm{C}$. The second highest peak $f_{x}$ $\left(f_{x}=5.61\right)$ occurred on day 13 in Wuhan at $22^{\circ} \mathrm{C}$. Double peak 


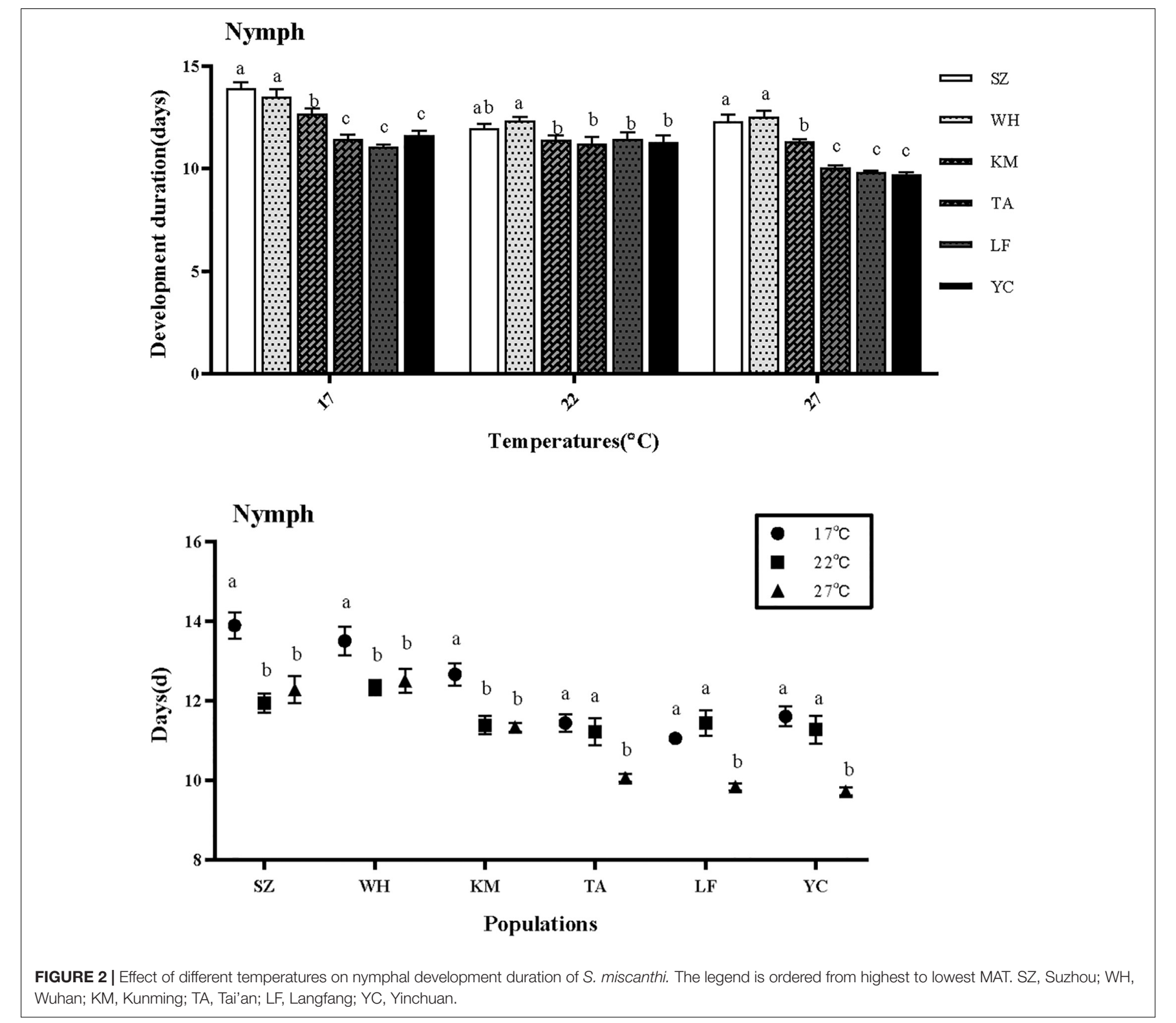

of $l_{x} m_{x}$ appeared in Suzhou and Wuhan of Southern populations at 17 and $22^{\circ} \mathrm{C}$ (Figure 7).

\section{DISCUSSION}

Insects are poithermic animals, and their ability to maintain and regulate internal temperature is not strong. Environmental temperature affects the rate of all chemical reactions in their life activities. Therefore, temperature is a key variable that determines development, fecundity, population growth and survival of insects (Dean, 1974; Deutsch et al., 2008; Wang et al., 2021). In this study, artificial climate chamber were used to simulate different temperatures and to comprehensively evaluated their influences on the aphid population dynamics, survival rate, growth, development and of different latitude populations. The results showed that the change in environmental temperature exerted a certain influence on the growth, development, fecundity, and intrinsic growth rate of the aphid populations in different latitudes.

Relevant research indicates the influence of temperature on insect growth and reproduction. Ecological amplitude theory refers to the scope of biological organisms or a physiological process of biological organisms to adapt to ecological and environmental conditions (Oyama, 1994). There is an optimum zone in the ecological amplitude, in which the organism is in the best physiological condition, the highest reproduction rate and the greatest amount. The negative effects of low and high temperatures on population parameters have been observed in other species (Castillo et al., 2006).

The optimal temperature for the growth of Acyrthosiphon gossypii was $21-27^{\circ} \mathrm{C}$ (Gao et al., 2013), and that of S. avenae 

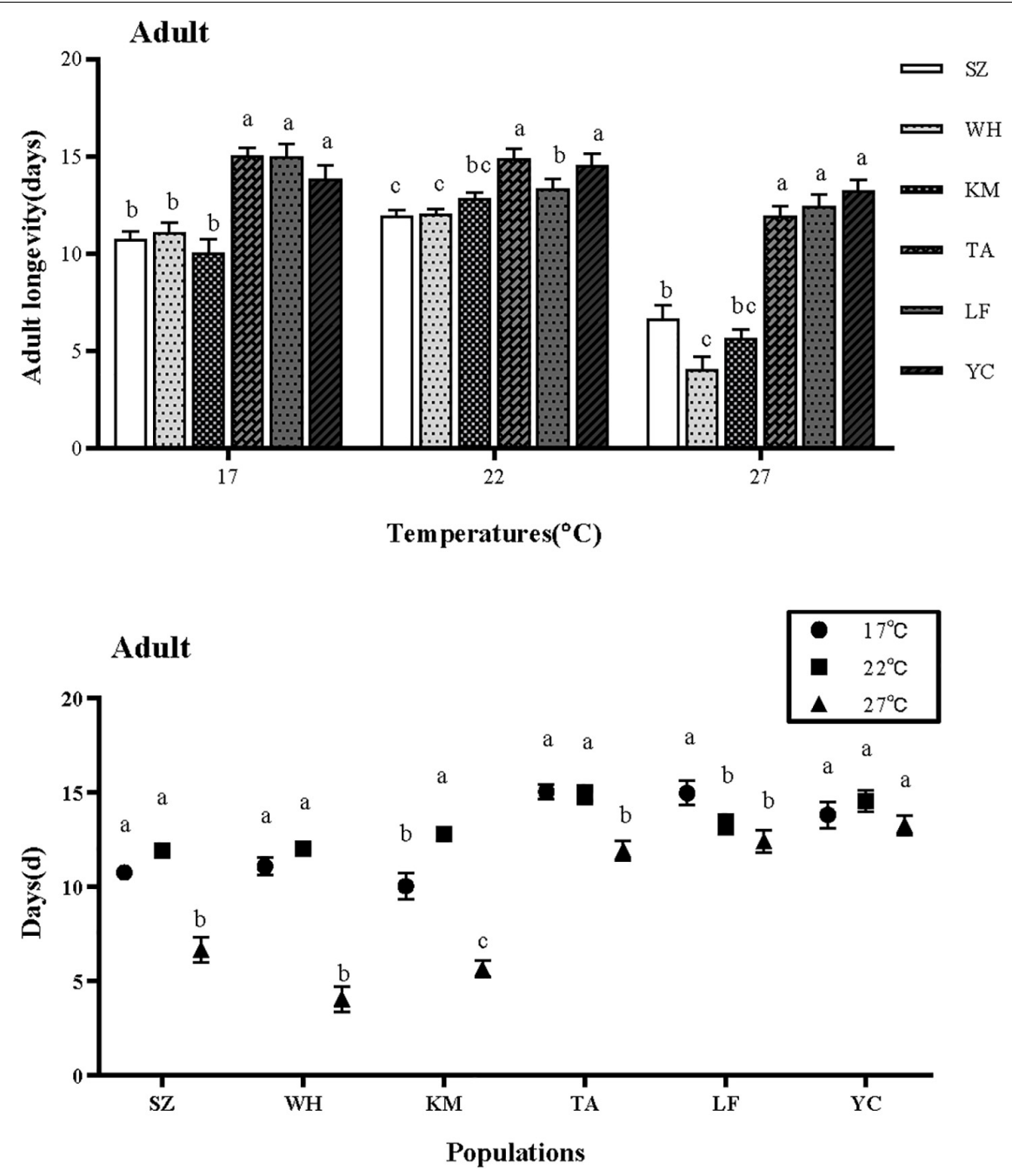

FIGURE 3 | Effect of different temperatures on adult longevity of S. miscanthi. SZ, Suzhou; WH, Wuhan; KM, Kunming; TA, Tai'an; LF, Langfang; YC, Yinchuan.

was $22.5^{\circ} \mathrm{C}$ (Lykouressis, 1985), Metopolophium dirhodum was $25^{\circ} \mathrm{C}$ (Zhou and Carter, 1992), Macrosiphum rosae was $22^{\circ} \mathrm{C}$ (Mehrparvar and Hatami, 2007). The results showed that the development and reproduction of $S$. miscanthi was regulated by temperature. S. Miscanthi showed a moderate temperature preference, with an optimum temperature range of $18-26^{\circ} \mathrm{C}$ (Yin et al., 2003)? In the suitable temperature range, the development duration of S. Miscanthi shortened with the increase of temperature, and the generation duration shortened by 1 day with the increase of temperature $1^{\circ} \mathrm{C}$ (Lykouressis, 1985). The amount of aphid increased with the increase of temperature. The reproductive peak was advanced, and the proportion of intrinsic growth rate, finite growth rate and the proportion of adult aphid increased gradually, reaching the maximum at $21-$ $22^{\circ} \mathrm{C}$ and decreasing at $26-27^{\circ} \mathrm{C}$. In addition, some studies have proved that when the temperature was higher than $27^{\circ} \mathrm{C}$, the adult aphid could not reproduce. When the temperature was higher than $30^{\circ} \mathrm{C}$, the development, survival and reproduction rate of aphid decreased and could not complete development, and the mortality rate of aphid reached 100\% (Kieckhefer et al., 1989; Asin and Pons, 2001). The development speed of Laodelphax striatellus was linearly related to temperature between 15 and $25^{\circ} \mathrm{C}$. At 30 or $32.5^{\circ} \mathrm{C}$, the relationship was no longer linear, and the variation increased (Hachiya, 1990). Temperatures higher than $32^{\circ} \mathrm{C}$ caused a decrease in the developmental rate of Aphis spiraecola (Wang and Tsai, 2000). In our study, it was also found that the nymph development period of S. miscanthi in northern China was shortened, the adult lifespan was increased, and the reproductive capacity was enhanced. In conclusion, within the suitable temperature range the fertility and intrinsic growth rate of wheat aphid increased with the increase of temperature, and the development period of wheat aphid decreased with the increase of temperature. However, the wheat aphid has poor heat resistance, and when the ambient temperature exceeded a certain limit, the life activities of wheat aphid would be seriously affected. Temperature has a significant effect on the physiological processes of insects, such as body size (Atkinson, 1994), mating behavior, feeding 

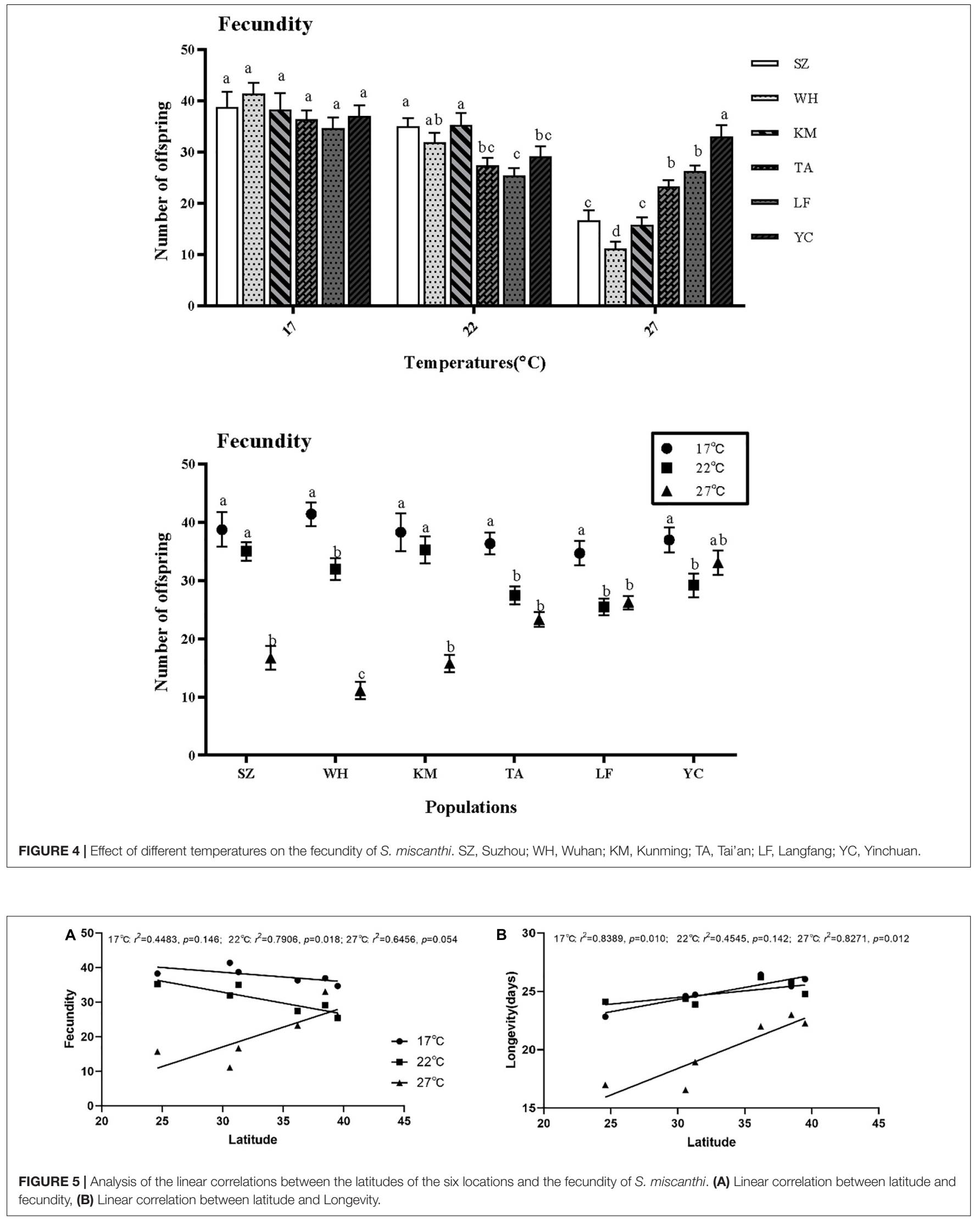


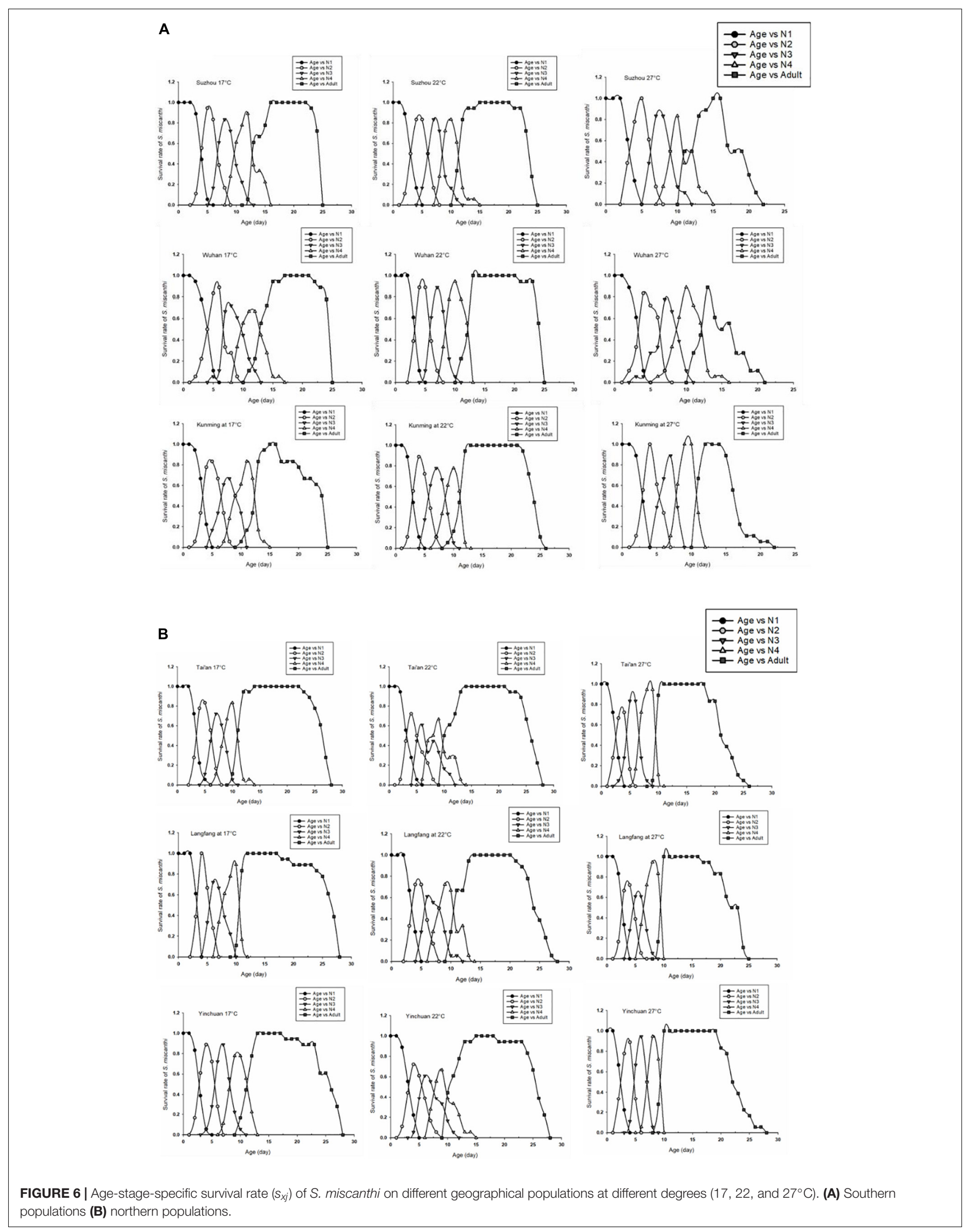


TABLE 2 | Life-table parameters at each location at different temperatures.

\begin{tabular}{|c|c|c|c|c|c|}
\hline $\operatorname{Temp}\left({ }^{\circ} \mathbf{C}\right)$ & Location & $R_{0}($ Mean $\pm \mathrm{SE})$ & $T$ (Mean \pm SE) & $r_{\mathrm{m}}($ Mean $\pm \mathrm{SE})$ & $\lambda($ Mean \pm SE $)$ \\
\hline & $\mathrm{SZ}$ & $38.722 \pm 0.182 b$ & $18.727 \pm 0.022 a$ & $0.195 \pm 0.001 f$ & $1.216 \pm 0.001 f$ \\
\hline & WH & $41.389 \pm 0.049 a$ & $18.323 \pm 0.008 b$ & $0.203 \pm 0.001 c$ & $1.225 \pm 0.001 c$ \\
\hline \multirow[t]{6}{*}{17} & $\mathrm{KM}$ & $38.278 \pm 0.067 c$ & $17.184 \pm 0.008 e$ & $0.212 \pm 0.001 b$ & $1.236 \pm 0.001 b$ \\
\hline & TA & $36.333 \pm 0.081 e$ & $18.040 \pm 0.045 c$ & $0.199 \pm 0.001 \mathrm{e}$ & $1.220 \pm 0.001 e$ \\
\hline & LF & $34.667 \pm 0.096 f$ & $17.583 \pm 0.018 d$ & $0.202 \pm 0.001 d$ & $1.223 \pm 0.001 d$ \\
\hline & YC & $36.944 \pm 0.121 d$ & $16.913 \pm 0.037 f$ & $0.213 \pm 0.001 a$ & $1.238 \pm 0.001 a$ \\
\hline & $\mathrm{SZ}$ & $35.000 \pm 0.081 a$ & $16.148 \pm 0.004 d$ & $0.220 \pm 0.001 b$ & $1.246 \pm 0.001 b$ \\
\hline & WH & $31.944 \pm 0.145 b$ & $17.059 \pm 0.040 c$ & $0.203 \pm 0.001 c$ & $1.225 \pm 0.001 c$ \\
\hline \multirow[t]{6}{*}{22} & $\mathrm{KM}$ & $35.278 \pm 0.236 a$ & $15.964 \pm 0.010 \mathrm{e}$ & $0.223 \pm 0.001 a$ & $1.250 \pm 0.001 a$ \\
\hline & TA & $27.444 \pm 0.032 d$ & $17.589 \pm 0.050 b$ & $0.188 \pm 0.001 \mathrm{e}$ & $1.207 \pm 0.001 e$ \\
\hline & LF & $25.444 \pm 0.081 e$ & $17.886 \pm 0.053 a$ & $0.181 \pm 0.001 f$ & $1.198 \pm 0.001 f$ \\
\hline & YC & $29.167 \pm 0.067 c$ & $17.493 \pm 0.044 b$ & $0.193 \pm 0.001 d$ & $1.213 \pm 0.001 d$ \\
\hline & SZ & $16.667 \pm 0.049 d$ & $14.843 \pm 0.052 b$ & $0.190 \pm 0.001 d$ & $1.209 \pm 0.001 d$ \\
\hline & $\mathrm{WH}$ & $11.111 \pm 0.067 f$ & $13.670 \pm 0.070 c$ & $0.176 \pm 0.001 e$ & $1.193 \pm 0.001 e$ \\
\hline \multirow[t]{4}{*}{27} & $\mathrm{KM}$ & $15.722 \pm 0.085 \mathrm{e}$ & $13.078 \pm 0.061 d$ & $0.211 \pm 0.001 c$ & $1.235 \pm 0.001 c$ \\
\hline & TA & $23.278 \pm 0.103 c$ & $14.768 \pm 0.029 b$ & $0.213 \pm 0.001 b$ & $1.238 \pm 0.001 b$ \\
\hline & LF & $26.222 \pm 0.067 b$ & $14.623 \pm 0.032 b$ & $0.223 \pm 0.001 a$ & $1.250 \pm 0.001 a$ \\
\hline & YC & $33.056 \pm 0.081 a$ & $15.439 \pm 0.088 a$ & $0.227 \pm 0.001 a$ & $1.254 \pm 0.001 a$ \\
\hline
\end{tabular}

$R_{0}:$ The reproductive rate; $r_{m}$ : the intrinsic rate of population increase; $T$ : the generation average period; $\lambda$ : the weekly growth rate.

ability, immune function (Karl and Fischer, 2008; Karl et al., 2011). Because the age-stage, two-sex life table take into account all of the environment factors, offers the most comprehensive understanding of these parameters (such as developmental rate, survival rate, fecundity etc.), therefore, it is worth to be applied in these researches.

In addition, geographical factors exhibit a certain correlation with the reproductive ability and longevity of aphids at different temperatures. In this study, the developmental duration of the southern population decreased from 17 to $22^{\circ} \mathrm{C}$, while that of the northern population decreased from 22 to $27^{\circ} \mathrm{C}$. The nymph development period in the northern region is obviously shorter than that in the southern region, and the longevity of adults was longer than that of southern populations at the three temperatures. The fecundity of northern populations was significantly lower than that of southern populations at $22^{\circ} \mathrm{C}$, however, higher at $27^{\circ} \mathrm{C}$. With the increase of temperature, the fecundity of northern population gradually decreased from 22 to $27^{\circ} \mathrm{C}$, and there's no significant difference between 22 and $27^{\circ} \mathrm{C}$, while the southern population suddenly decreased at $27^{\circ} \mathrm{C}$. $l_{x}$ of southern populations began to decline rapidly on 15 days of age at $27^{\circ} \mathrm{C}$, while those of northern populations were not significantly affected until on 20 days of age. These findings are somewhat surprising given that another research corroborates the hypothesis of "the hotter the better" southern populations are generally more fecundity than northern populations (Huang et al., 2015). Although our results do not quite agree with the hypothesis of "the hotter the better". But from our result we found that the fecundity of northern populations was significantly lower than that of southern populations at $22^{\circ} \mathrm{C}$, which agree with the hypothesis. However, higher at $27^{\circ} \mathrm{C}$ (Figure 5). We considered that $27^{\circ} \mathrm{C}$ is not the suitable degree for the reproduction of the aphids. We proved that aphid populations in the north have a wider ecological amplitude, that northern aphids adapt to higher temperatures, develop faster at higher temperatures. Some studies have proved that insects in lower latitudes (southern regions) have higher fertility ability because that the higher temperatures accelerate growth and development of nymphs. But our result proved that the higher reproductive rate of southern regions requires organisms to live at the suitable ambient temperature.

On the basis of the law of conservation of energy, we speculate that the shorter developmental period in the northern populations led to their advantages in fecundity. The tradeoff is the negative correlation between these two life history of development duration and fecundity (Cingolani et al., 2019). Multiple mating increased reproduction in Edessa meditabunda (Hemiptera: Pentatomidae), and the cost of increasing fecundity was the reduction of longevity (Guerra and Pollack, 2007; Silva et al., 2012). In this study, there was also significant negative correlation between development duration of nymph and fecundity of adult. The nymph development period in northern China was shorter than that in southern China, and the fecundity was higher than that in southern China in $27^{\circ} \mathrm{C}$.

In particular, the longevity of adult aphid in Yinchuan was not affected by temperature increase, indicating that aphids in high latitudes display larger thermal tolerance ranges. The reproductive rates of populations from various locations declined with increasing temperature, except that of the Yinchuan population, which may have been affected by its high latitude and unique geographical environment. Organisms at higher latitudes have greater environmental variability over the course of a year. The peaks of agestage fecundity $\left(f_{x j}\right)$, age-specific fecundity $\left(m_{x}\right)$, and agespecific net maternity $\left(l_{x} m_{x}\right)$ were all occurred in the northern populations, and the peak value appeared earlier in the north 
A
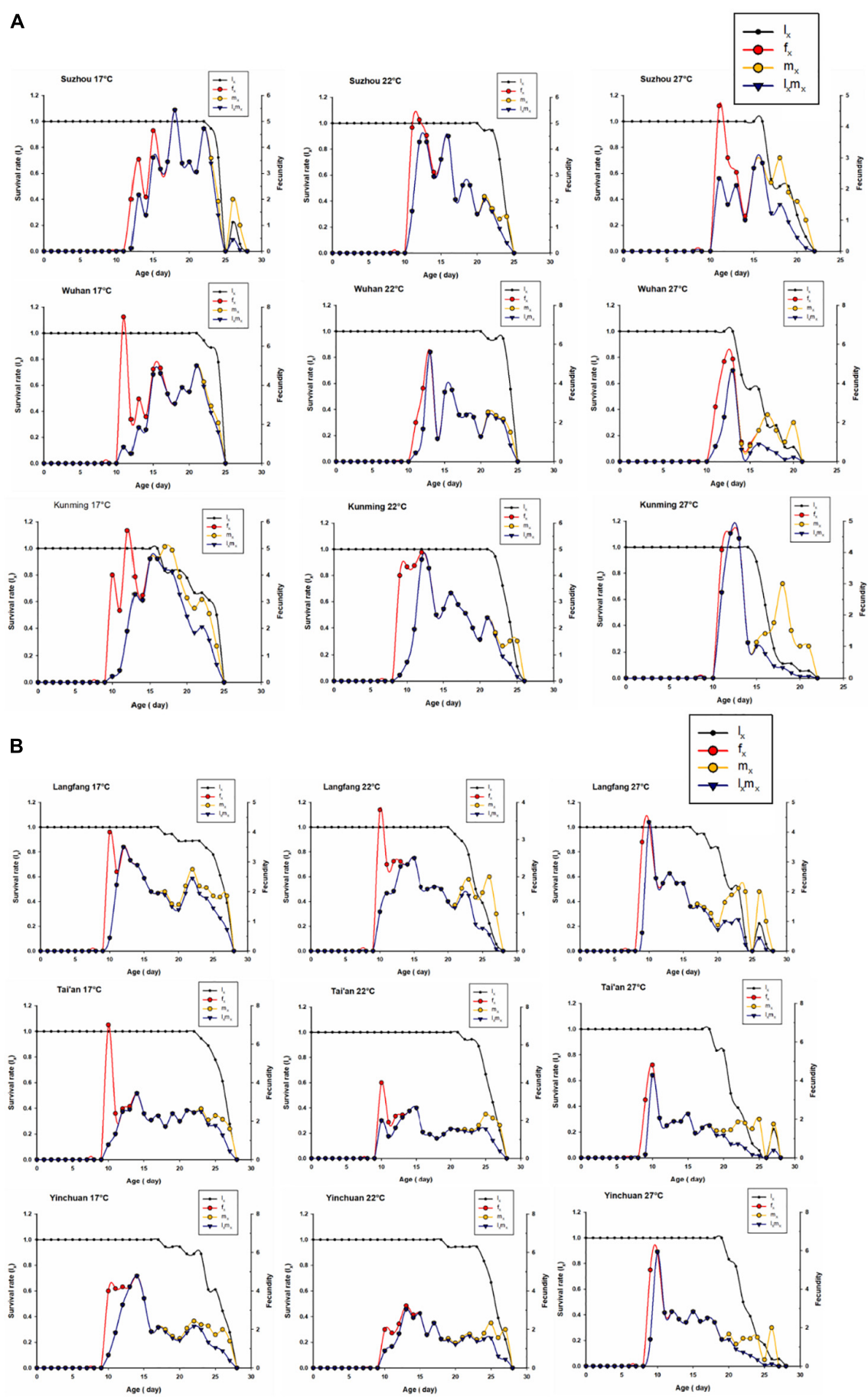

FIGURE 7 | Age-specific survival rate $\left(\|_{x}\right)$, age-stage fecundity $\left(f_{x j}\right)$, age-specific fecundity $\left(m_{x}\right)$, and age-specific maternity $\left(\|_{x} m_{x}\right)$ of $S$. miscanthi on different geographical populations at different degrees $\left(17,22\right.$, and $\left.27^{\circ} \mathrm{C}\right)$. (A) Southern populations (B) northern populations.

than in the south. Insects have a smaller thermal tolerance at low latitudes but a large thermal tolerance at high latitudes (Huey and Kingsolver, 1989), This finding is similar to the results of our research. Therefore, geographical conditions are potential factors affecting the growth, development and fecundity of aphids.
On the other hand, we speculated that because southern China is not a major wheat-producing area, the low genetic diversity of aphids in the region has led to poor overall adaptability in southern aphids (Sun et al., 2022). This result may be explained by the fact that there are migratory behaviors among aphids from different populations. We've shown that in previous 
studies that wheat aphids generally move northward with the southwesterly airflow in March and then move southwardly with the northwesterly wind after August to become a source of insects on autumn seedlings in winter wheat areas in China (Sun et al., 2022). Therefore, the population samples of aphids collected in the same place may be different, be partly from native aphids and partly from migratory aphids, which also leads to uncertainty in the results. The possible interference of migration cannot be ruled out. Therefore, further studies are required to evaluate the impacts of aphid migration.

The microenvironment in which insects live yields temperature heterogeneity (Sinoquet et al., 2007; Kearney et al., 2009). Organisms can alleviate the negative effects of climate change by generating mobile bodies in the microclimate of the habitat: that is, through thermo regulation. S. avenae can take advantage of the spatial heterogeneity of the microenvironment it inhabits and transfer itself to the moist soil surface through thermoregulation to avoid the adverse effects of high temperature (Kearney et al., 2009). In addition, some studies have found that some hormone regulation plays a role in the development and reproduction of insects. Many hormone changes are influenced by environmental changes (Addo-Bediako et al., 2002). Candidate genes of insulin signaling and Wnt signaling participating in circadian rhythmicity, which are pathways previously associated with insect diapause development, are also affected by environmental changes (Koštál et al., 2017). Insulin-like and testis ecdysiotropin neuropeptides are regulated by the circadian timing system in the brain during larval-adult development in the insect Rhodnius prolixus (Hemiptera) (Vafopoulou and Steel, 2012). Bombyxin -8 gene plays an important role in the development, silk protein synthesis and egg diapause of silkworm (Zheng et al., 2016). Epigenetic modification can also affect the development and reproduction of insects. DNA methylation impacted by temperature change regulates female fecundity in Nilaparvata lugens (Zhang et al., 2015). And also made changes induced by long and short photoperiods in Nasonia and aphids (Pasquier et al., 2014; Pegoraro et al., 2016). Such as aphids, photoperiod regulates the production of seasonal morphs, with short nights of summer inducing parthenogenetic virginoparae, whereas the long nights of autumn lead to the production of sexual forms (oviparae), which inturn may lay diapausing eggs (Saunders, 2012). The photoperiod and the gene or signaling referred to hormonal regulation and epigenetic modification have been hinted to be important in aphid development and reproduction, and we will try to carry out relevant research in future studies.

Many insects adopt behavioral strategies to regulate their body temperature. Therefore, when we study the impact of temperature on population relationships, we will also consider the role of thermoregulatory behavior strategies. Assessing facultative endosymbionts in the different populations better reveals aphid thermal tolerance (Burke et al., 2009; Ferrari et al., 2020). There are close links between aphid responses to heat and to infection. The endosymbiont-associated cereal aphid thermal performance needs to be determined in the future. In our study, we did not set the extreme temperature, which is the survival temperature of the insects. Many studies have proved that under the warming climate, extreme high temperature occurs frequently, which has a great impact on the development and reproduction of insects, namely the production and yield of crops ( $\mathrm{Ma}$ and $\mathrm{Ma}, 2012$ ). The study involving impacts of extreme thermal temperatures on aphids population fitness deserve further research.

Strengthening the study of insect reproductive strategies to cope with adverse temperature environment could lead to a more complete understanding of insect reproductive physiology, and could also make the forecast and control of insect pests more accurate and effective. With the rise of transcriptomics, genomics, metabolomics and other omics, future studies will explore the mechanism of temperature affecting reproduction and the interaction between these mechanisms from an overall perspective. This study clarified the effects of different temperatures on the development and reproduction of different geographical populations of $S$. miscanthi. The results provide a theoretical basis for predicting potential aphid outbreak locations. The e effect of temperature on aphid control efficiency and population fitness by influencing aphid growth and reproduction has been estimated in many previous studies, such as one on aphid braconidae (McCalla et al., 2019). Our result proved that the higher reproductive rate of southern population requires aphids to live at the suitable ambient temperature, and aphid populations in the north have a wider ecological amplitude. The results will be helpful for predicting the potential aphid outbreaks in China's main wheat areas under suitable conditions. Therefore, our study also provides a theoretical basis for aphid control under future climate change. The wheat aphid in northern China has a wide ability to adapt to temperature, and may have stronger damage potential and adaptability under future climate warming, which is the focus of field control.

\section{DATA AVAILABILITY STATEMENT}

The original contributions presented in the study are included in the article/Supplementary Material, further inquiries can be directed to the corresponding authors.

\section{AUTHOR CONTRIBUTIONS}

JS: conceptualization, methodology, software, validation, formal analysis, investigation, data calculation, writing, original draft preparation, editing, and visualization. XT: conceptualization, methodology, wring, and editing. QL: software and investigation. FF: conceptualization, supervision, and project administration. JC: conceptualization, methodology, supervision, project administration, and funding acquisition. All authors have read and agreed to the published version of the manuscript.

\section{FUNDING}

This research was funded by National Key R\&D Program of China (2017YFD0201700 and 2016YFD03007) and National Science Foundation of China (31700343 and 32172415). 


\section{ACKNOWLEDGMENTS}

We would like to thank Zhongkai Zhao for his help in the laboratory work, and to Yu Chen for her advice in the statistical analyses.

\section{REFERENCES}

Addo-Bediako, A., Chown, S., and Gaston, K. (2002). Metabolic cold adaptation in insects: a large-scale perspective. Funct. Ecol. 16, 332-338. doi: 10.1046/j.13652435.2002.00634.x

Ahn, J. J., Cho, J. R., Kim, J. H., and Bo, Y. S. (2020). Thermal effects on the population parameters and growth of Acyrthosiphon pisum (harris) (hemiptera: aphididae). Insects 11:481. doi: 10.3390/insects11080481

Angilletta, M. J. (2009). Thermal Adaptation: A Theoretical and Empirical Synthesis Oxford: Oxford University Press.

Asin, L., and Pons, X. (2001). Effect of high temperature on the growth and reproduction of corn aphids (Homoptera: Aphididae) and implications for their population dynamics on the northeastern Iberian Peninsula. Environ. Entomol. 30, 1127-1134. doi: 10.1603/0046-225X-30.6.1127

Atkinson, D. (1994). Temperature and organism size: a biological law for ectotherms? Adv. Ecol. Res. 25, 1-58.

Bernard, S., Baleba, S., Sevilor, K., Samuel, N., and Nanga, M. (2018). Effect of temperature on the biological parameters of the cabbage aphid Brevicoryne brassicae. Ecol. Evol. 8, 11819-11832. doi: 10.1002/ece 3.4639

Blackman, R. L., and Eastop, V. F. (1984). Aphids on the World's Crops: An Identification Guide. New York, NY: Wiley Press.

Burke, G. R., Normark, B. B., Favret, C., and Moran, N. A. (2009). Evolution and diversity of facultative symbionts from the aphid subfamily Lachninae. Appl. Environ. Microb. 75, 5328-5335. doi: 10.1128/aem.00717-09

Castillo, J., Jacas, J. A., Pena, J. E., Ulmer, B. J., and Hall, D. G. (2006). Effect of temperature on life history of Quadrastichus haitiensis (Hymenoptera: Eulophidae), an endoparasitoid of Diaprepes abbreviatus (Coleoptera: Curculionidae). Biol. Control 36, 189-196. doi: 10.1016/j.biocontrol.2005.09. 023

Chen, C. Y., Chiu, M. C., and Kuo, M. H. (2013). Effect of warming with temperature oscillations on a low-latitude aphid, Aphis craccivora. Bull. Entomol. Res. 103, 406-413. doi: 10.1017/S0007485312000867

Chen, J., Wang, Y., Shen, Z., Zhu, Z., Song, Y., and Han, R. (2011). Early diagnostic value of plasma PCT and BG assay for CRBSI After OLT. Transplant. Proc. 43, 1777-1779. doi: 10.1016/j.transproceed.2010.11.026

Chi, H., and Su, H.-Y. (2006). Age-stage, Two-sex life tables of Aphidius gifuensis (Ashmead) (Hymenoptera: Braconidae) and its host Myzus persicae (Sulzer) (Homoptera: Aphididae) with mathematical proof of the relationship between female fecundity and the net reproductive rate. Environ. Entomol. 35, 10-21. doi: 10.1603/0046-225X-35.1.10

Cingolani, M. F., Roggiero, M. F., Barakat, M. C., and Liljesthrm, G. G. (2019). Polyandry and trade-off between fecundity and longevity in female Dichelops furcatus (Hemiptera: Pentatomidae). Bull. Entomol. Res. 110, 155-160. doi: 10.1017/S0007485319000427

Clarke, A. (1993). Seasonal acclimatization and latitudinal compensation in metabolism: do they exist? Funct. Ecol. 7:139. doi: 10.2307/2389880

David, S. K. (1975). A taxonomic review of Macrosiphum (Homoptera:Aphiddiae) in India. Orient. Insects 9, 461-493. doi: 10.1080/00305316.1975.10434515

Davison, R., Jacquemyn, H., Adriaens, D., Honnay, O., Kroon, H. D., and Tuljapurkar, S. (2010). Demographic effects of extreme weather events on a short-lived calcareous grassland species: stochastic life table response experiments. J. Ecol. 98, 255-267. doi: 10.1111/j.1365-2745.2009.01611.x

Dean, G. J. (1974). Effect of temperature on the cereal aphids Metopolophium dirhodum (Wlk.), Rhopalosiphum padi (L.) and Macrosiphum avenue (F.) (Hem., Aphididae). Bull. Entomol. Res. 63, 401-409. doi: 10.1017/ S0007485300040888

\section{SUPPLEMENTARY MATERIAL}

The Supplementary Material for this article can be found online at: https://www.frontiersin.org/articles/10.3389/fevo.2022. 794495/full\#supplementary-material

Del, P., and Reisig, D. (2013). First-generation Megacopta cribraria (Hemiptera: Plataspidae) can develop on soybeans. J. Econ. Entomol. 106, 533-535. doi: $10.1603 / \mathrm{EC} 12425$

Denlinger, D. L. (2002). Regulation of Diapause. Annu. Rev. Entomol. 47, 93-122. doi: 10.1146/annurev.ento.47.091201.145137

Deutsch, C. A., Tewksbury, J. J., Huey, R. B., Sheldon, K. S., Ghalambor, C. K., Haak, D. C., et al. (2008). Impacts of climate warming on terrestrial ectotherms across latitude. P. Natl. Acad. Sci. U.S.A. 105, 6668-6672. doi: 10.1073/pnas. 0709472105

Ferrari, J., Smee, M. R., and Heyworth, E. R. (2020). Aphid facultative symbionts aid recovery of their obligate symbiont and their host after heat stress. Front. Ecol. Evol. 8:10. doi: 10.3389/fevo.2020.00056

Gao, G. Z., Perkins, L. E., Zalucki, M. P., Lu, Z. Z., and Ma, J. H. (2013). Effect of temperature on the biology of Acyrthosiphon gossypii Mordvilko (Homoptera: Aphididae) on cotton. J. Pest Sci. 86, 167-172. doi: 10.1007/s10340-012-0470-x

Guerra, P. A., and Pollack, G. S. (2007). A life history trade-off between flight ability and reproductive behavior in male field crickets (gryllus texensis). J. Insect Behav. 20, 377-387. doi: 10.1007/s10905-007-9084-1

Hachiya, K. (1990). Effect of temperature on the developmental velocity of the small brown planthopper, Laodelphax striatellus, Fallén. Ann. Rep. Soc. Plant Prot. North JP 41, 112-113.

Hajar, P., Yaghoub, F., and Annie, E. (2011). Effect of temperature on life table parameters of predatory thrips Scolothrips longicornis (Thysanoptera: Thripidae) fed on twospotted spider mites (Acari: Tetranychidae). J. Econ. Entomol. 104, 799-805. doi: 10.1603/EC10144

Hales, D. F., Chapman, R. L., Lardner, R. M., Cowen, R., and Turak, E. (2010). Aphids of the genus sitobion occurring on grasses in southern Australia. Austral. Entomol. 29, 19-25. doi: 10.1111/j.1440-6055.1990.tb00308.x

Han, Z. L., Tan, X. L., Wang, Y., Xu, Q. X., Zhang, Y., Harwood, J. D., et al. (2019). Effects of simulated climate warming on the population dynamics of Sitobion avenae (Fabricius) and its parasitoids in wheat fields. Pest Manag. Sci. 75, 3252-3259. doi: 10.1002/ps.5447

Hawkes, J. R., and Jones, R. (2005). Incidence and distribution of Barley yellow dwarf virus and Cereal yellow dwarf virus in over-summering grasses in a Mediterranean-type environment. Aust. J. Agric. Res. 56, 257-270. doi: 10.1071/ AR04259

Hochachka, P. W., and Somero, G. N. (2002). Biochemical Adaptation: Mechanism and Process in Physiological Evolution. Oxford: Oxford University Press.

Huang, X., Liu, D., Wang, D., Shi, X., and Simon, J. C. (2015). Molecular and quantitative genetic differentiation in Sitobion avenae populations from both sides of the Qinling Mountains. PLoS One. 10:e0122343. doi: 10.1371/journal. pone. 0122343

Huang, Y. B., and Chi, H. (2012). Age-stage, two-sex life tables of Bactrocera cucurbitae (Coquillett) (Diptera: Tephritidae) with a discussion on the problem of applying female age-specific life tables to insect populations. Insect Sci. 19, 263-273. doi: 10.1111/j.1744-7917.2011.01424.x

Huey, B., and Kingsolver, J. G. (1993). Evolution of Resisitance to High Tempera in Ectotherms. Chicago: University of Chicago Press.

Huey, R. B., and Kingsolver, J. G. (1989). Evolution of thermal sensitivity of ectotherm performance. Trends Ecol. Evol. 4, 131-135. doi: 10.1016/01695347(89)90211-5

Jin, M. C., Zheng, W. H., Zhang, Y. Q., Gao, B. Y., and Yu, L. L. (2021). Lipid compositions and geographical discrimination of 94 geographically authentic wheat samples based on UPLC-MS with non-targeted lipidomic approach. Foods 10:10. doi: 10.3390/foods 10010010

Karl, I., and Fischer, K. (2008). Why get big in the cold? Towards a solution to a life-history puzzle. Oecologia 155, 215-225. doi: 10.1007/s00442-007-0902-0 
Karl, I., Stoks, R., Deblock, M., Janowitz, S. A., and Fischer, K. (2011). Temperature extremes and butterfly fitness: conflicting evidence from life history and immune function. Glob. Change Biol. 17, 676-687. doi: 10.1111/j.1365-2486. 2010.02277.x

Kearney, M., Shine, R., and Warren, P. P. (2009). The potential for behavioral thermoregulation to buffer "cold-blooded" animals against climate warming. P. Natl. Acad. Sci. U.S.A. 106, 3835-3840. doi: 10.1073/pnas.0808913106

Kieckhefer, R. W., Elliott, N. C., and Walgenbach, D. D. (1989). Effects of constant and fluctuating temperatures on developmental rates and demographic statistics of the English grain aphid (Homoptera: Aphididae). Ann. Entomol. Soc. Am. 82, 701-706. doi: 10.1093/aesa/82.6.701

Kingsolver, J. G. (2009). The well-temperatured biologist. (American Society of Naturalists Presidential Address). Am. Nat. 174, 755-768. doi: 10.1086/648310

Kirkegaard, J., Christen, O., Krupinsky, J., and Layzell, D. (2008). Break crop benefits in temperate wheat production. Field Crop. Res. 107, 185-195. doi: 10.1016/j.fcr.2008.02.010

Koštál, V., Štitina, T., Poupardin, R., Korbelová, J., and Bruce, A. W. (2017). Conceptual framework of the eco-physiological phases of insect diapause development justified by transcriptomic profiling. Proc. Natl. Acad. Sci. U.S.A. 114, 8532-8537. doi: 10.1073/pnas.1707281114

Kroschel, J., Sporleder, M., Tonnang, H. E. Z., Juarez, H., Carhuapoma, P., Gonzales, J. C., et al. (2013). Predicting climate-change-caused changes in global temperature on potato tuber moth Phthorimaea operculella (Zeller) distribution and abundance using phenology modeling and GIS mapping. Agr. Forest Meteorol. 170, 228-241. doi: 10.1016/j.agrformet.2012.06.017

Liao, Q. J., Yang, Y. J., Wang, J., Pang, X., and Liu, Y. H. (2017). Temperaturedependent development and reproduction of rice leaffolder, Marasmia exigua (Lepidoptera: Pyralidae). PLoS One 12:e0187972. doi: 10.1371/journal.pone. 0187972

Luis, A., and Xavier, P. (2001). Effect of high temperature on the growth and reproduction of corn aphids (homoptera: aphididae) and implications for their population dynamics on the northeastern iberian peninsula. Environ. Entomol. 30, 1127-1134.

Lykouressis, D. P. (1985). Temperature requirements of Sitobion avenae (F.) necessary for ecological studies, by assessing methods for the estimation of instar duration. Zeits. Ang. Entomol. 100, 479-493. doi: 10.1111/j.1439-0418. 1985.tb02810.x

Ma, G., and Ma, C. S. (2012). Climate warming may increase aphids' dropping probabilities in response to high temperatures. J. Insect Physiol. 58, 1456-1462. doi: $10.1016 /$ j.jinsphys.2012.08.012

Ma, G., and Ma, C. S. (2016). The impacts of extreme high temperature on insect populations under climate change: a review. Sci. Sin. 46, 556-564. doi: 10.1360/ N052016-00037

Maia Ade, H., Luiz, A. J., and Campanhola, C. (2000). Statistical inference on associated fertility life table parameters using jackknife technique: computational aspects. J. Econ. Entomol. 93, 511-518. doi: 10.1603/0022-049393.2.511

McCalla, K. A., Keçeci, M., Milosavljević, I., Ratkowsky, D. A., and Hoddle, M. S. (2019). The influence of temperature variation on life history parameters and thermal performance curves of Tamarixia radiata (Hymenoptera: Eulophidae), a parasitoid of the Asian Citrus Psyllid (Hemiptera: Liviidae). J. Econ. Entomol. 112, 1560-1574. doi: 10.1093/jee/toz067

Mehrparvar, M., and Hatami, B. (2007). Effect of temperature on some biological parameters of an Iranian population of the Rose Aphid, Macrosiphum rosae (Hemiptera: Aphididae). Eur. J. Entomol. 104, 631-634. doi: 10.14411/eje.2007. 078

Nirmal, R. C., Furtado, A., Rangan, P., and Henry, R. J. (2017). Fasciclin-like arabinogalactan protein gene expression is associated with yield of flour in the milling of wheat. Sci. Rep. 7:12539. doi: 10.1038/s41598-017-12845-y

Nyaanga, J. G., Kamau, A. W., and Wanjama, J. (2005). The influence of temperature on population increase and alarysym of three aphid species. Discov. Innovat. 17, 117-121. doi: 10.4314/dai.v17i3.15730

Osawa, N. (1993). Population field studies of the aphidophagous ladybird beetle Harmonia axyridis (Coleoptera:Coccinellidae): life tables and key factor analysis. Res. Popul. Ecol. 35, 335-348. doi: 10.1007/BF02513605

Oyama, K. (1994). Ecological amplitude and differentiation among populations of Arabis serrata (brassicaceae). Int. J. Plant Sci. 155, 220-234. doi: 10.1086/297161
Pasquier, C., Clément, M., Dombrovsky, A., Penaud, S., Da Rocha, M., Rancurel, C., et al. (2014). Environmentally selected aphid variants in clonality context display differential patterns of methylation in the genome. PLoS One 9:e115022. doi: 10.1371/journal.pone.0115022

Pegoraro, M., Bafna, A., Davies, N. J., Shuker, D. M., and Tauber, E. (2016). DNA methylation changes induced by long and short photoperiods in Nasonia. Genome Res. 26, 203-210. doi: 10.1101/gr.196204.115

Plessis, H. D., Schlemmer, M. L., and Berg, J. (2020). The effect of temperature on the development of Spodoptera frugiperda (Lepidoptera: Noctuidae). Insects 11:228. doi: 10.3390/insects11040228

Raychaudhuri, D. N., Ghosh, M. R., Banerjee, M., and Ghosh, A. K. (1973). Studies on the aphids (Homoptera: Aphididae) from Eastern India 14. One new genus, two new subgenera and fifteen new species of Greenideini. Kontyu 41, 53-73. doi: 10.1080/00305316.1977.10434544

Rock, G. C., and Shaffer, P. L. (1983). Developmental rates of Codling moth (Lepidoptera: Olethreutidae) reared on apple at four constant temperatures. Environ. Entomol. 12, 831-834. doi: 10.1093/ee/12.3.831

Saunders, D. S. (2012). Insect photoperiodism:seeing the light. Physiol. Entomol. $37,207-218$.

Silva, C., Laumann, R. A., Ferreira, J., Moraes, M., Borges, M., and Andrej, O. (2012). Reproductive biology, mating behavior, and vibratory communication of the brown-winged stink bug, Edessa meditabunda (Fabr.) (Heteroptera: Pentatomidae). Psyche. J. Entomol. 2012:598086. doi: 10.1155/2012/59 8086

Singh, R., Srivastava, A., and Kumar, U. (2009). Seasonal history of Sitobion miscanthi (Takahashi) (Homoptera: Aphididae) in terai of eastern Uttar Pradesh. J. Aphidol. 23, 43-48.

Sinoquet, H., Combes, D., and Casas, J. (2007). Regional climatic conditions modulate the within-tree mosaic of favourable and risky microclimates for insects. J. Anim. Ecol. 76, 424-438. doi: 10.1111/j.1365-2656.2007. 01231.x

Stange, E. E., and Ayres, M. P. (2010). Climate Change Impacts: Insects. New Jersey, NJ: John Wiley \& Sons, Ltd.

Suleman, M., and Reisen, W. K. (1979). Culex quinque fasciatus say: life table characteristics of adults reared from wild-caught pupae from North West Frontier Province. Pakistan. Mosquito News 39, 756-762.

Sun, J. X., Li, Q., Tan, X. L., Fan, J., Zhang, Y., Qin, Y. G., et al. (2022). Population genetic structure of Sitobion miscanthi in China. J. Integr. Agr. 21, 178-187. doi: 10.1016/S2095-3119(20)63445-1

Turak, E., Talent, R., Sunnucks, P., and Hales, D. F. (1998). Different responses to temperature in three closely-related sympatric cereal aphids. Entomol. Exp. Appl. 86, 49-58. doi: 10.1046/j.1570-7458.1998.00264.x

Vafopoulou, X., and Steel, C. G. (2012). Insulin-like and testis ecdysiotropin neuropeptides are regulated by the circadian timing system in the brain during larval-adult development in the insect Rhodnius prolixus (Hemiptera). Gen. Comp. Endocr. 179, 277-288. doi: 10.1016/j.ygcen.2012.08.018

Wang, D. H., Liu, Q., Jones, H. D., Bruce, T., and Xia, L. Q. (2014). Comparative transcriptomic analyses revealed divergences of two agriculturally important aphid species. BMC Genomics 15:1023. doi: 10.1186/1471-2164-15-1023

Wang, J. J., and Tsai, J. H. (2000). Effect of temperature on the biology of Aphis spiraecola (Homoptera: Aphididae). Ann. Entomol. Soc. Am. 93, 874-883. doi: 10.1109/TCAD.2002.807888

Wang, Y., Yan, J., Sun, J. R., Shi, W. P., Harwood, J. D., Monticelli, L. S., et al. (2021). Effects of field simulated warming on feeding behavior of Sitobion avenae (Fabricius) and host defense system. Entomol. Gen. 41, 567-578. doi: 10.1127/entomologia/2021/1271

Wang, Z., Shen, Z. R., Song, Y., Liu, H. Y., and Li, Z. X. (2009). Distribution and diversity of Wolbachia in different populations of the wheat aphid Sitobion miscanthi (Hemiptera: Aphididae) in China. Eur. J. Entomol. 106, 49-55. doi: 10.14411/eje.2009.007

Wei, D., Lu, H., Wu, Q., Yuan, G., and Fan, H. (2018). Comparative transcriptional profiling analysis of the effect of heat waves during embryo incubation on the hatchlings of the Chinese soft-shelled turtle (Pelodiscus sinensis). Ecol. Evol. 8, 3763-3773. doi: 10.1002/ece3.3850

Yin, Q. Y., Zheng, W. Y., Xie, X. S., Li, F., Li, R., Zheng, X. L., et al. (2003). The effect of temperature on development and fertility of Macrosiphum avenae. Acta Agr. Boreali Sin. 18, 71-73. 
Zhang, J., Xing, Y. R., Li, Y., Yin, C. L., Ge, C., and Li, F. (2015). DNA methyltransferases have an essential role in female fecundity in brown planthopper, Nilaparvata lugens. Biochem. Bioph. Res. Co. 464, 83-88. doi: 10. 1016/j.bbrc.2015.05.114

Zheng, X., Gong, Y., Kumar, D., Chen, F., Kuan, S., Liang, Z., et al. (2016). Effect of $B B X-B 8$ overexpression on development, body weight, silk protein synthesis and egg diapause of Bombyx mori. Transgenic Res. 25, 507-516. doi: 10.1007/ s11248-016-9947-3

Zhou, X., and Carter, N. (1992). ). Effects of temperature, feeding position and crop growth stage on the population dynamics of the rose grain aphid, Metopolophium dirhodum (Hemiptera: Aphididae). Ann. Appl. Biol. 121, 27-37. doi: 10.1111/j.1744-7348.1992.tb03984.x

Zhu, G., Xue, M., Luo, Y., Ji, G., Liu, F., Zhao, H., et al. (2017). Effects of short-term heat shock and physiological responses to heat stress in two Bradysia adults, Bradysia odoriphaga and Bradysia difformis. Sci. Rep. 7:13381. doi: 10.1038/ s41598-017-13560-4
Conflict of Interest: The authors declare that the research was conducted in the absence of any commercial or financial relationships that could be construed as a potential conflict of interest.

Publisher's Note: All claims expressed in this article are solely those of the authors and do not necessarily represent those of their affiliated organizations, or those of the publisher, the editors and the reviewers. Any product that may be evaluated in this article, or claim that may be made by its manufacturer, is not guaranteed or endorsed by the publisher.

Copyright (c) 2022 Sun, Tan, Li, Francis and Chen. This is an open-access article distributed under the terms of the Creative Commons Attribution License (CC BY). The use, distribution or reproduction in other forums is permitted, provided the original author(s) and the copyright owner(s) are credited and that the original publication in this journal is cited, in accordance with accepted academic practice. No use, distribution or reproduction is permitted which does not comply with these terms. 